\title{
Tradução e transgressão em Artaud e Herberto Helder
}

Izabela Leal

\section{Atividade tradutória e prática corporal}

Antonin Artaud, durante o período em que ficou internado no asilo psiquiátrico de Rodez, realizou algumas traduções, tendo começado por obras de Lewis Carroll e passado, em seguida, a Edgar Allan Poe, de quem traduziu o poema "Israfel". O contato com a obra de Poe foi decisivo na medida em que, através de uma prática de escrita e tradução, o poeta pôde reconstruir a sua relação com a linguagem e com o seu próprio corpo estilhaçado. Notável, a esse respeito, é o fato de o poema ter sido traduzido também por Baudelaire e Mallarmé, ambos referências essenciais por se terem, antes de Artaud, dedicado a uma reflexão meticulosa acerca da poesia.

Ao empreender a tradução de Poe, conforme afirma JeanMichel Rey no livro O nascimento da poesia [La naissance de la poésie], Artaud procura uma dicção própria, o que lhe possibilita restaurar o vínculo com a linguagem após o período de loucura, e, ao repetir o gesto de tradução já realizado por outros poetas de sua língua, inscrever-se também numa espécie de genealogia poética, por meio da qual traça uma linha de predecessores na poesia; genealogia essa que lhe permite tornar-se um autor.

Se, em 1947, ao publicar uma tradução de Through the looking glass, de Lewis Carroll, Artaud explicita que se tratava de um "projeto antigramatical a propósito de Lewis Carroll e contra ele"*, o poeta não faz mais do que retomar um pensamento que evidencia uma agressividade contra a linguagem, já formulado em seus escritos sobre teatro, mais especificamente em "Cartas sobre a crueldade" ["Lettres sur la cruauté"], de 1932: “[ ...] Eu reivindico [...] o direito de romper com o sentido usual da linguagem, que quebrar definitivamente a sua estrutura, de arrancar a coleira [...]”**.

O exercício de tradução presta-se perfeitamente a essa empresa antigramatical, já que evoca um problema de ordem prática: a relação entre o original e a versão. A distância produzida entre o texto original e o texto traduzido, a diferença

\footnotetext{
"entreprise antigramma. ticale à propos de Lewis Carroll et contre lui" (Rey, Jean-Michel. La naissance de la poésie: Antonin Artaud. Paris: Métailié, 1991: 68)

" "[...] "Je revendique $[\ldots]$ le droit de briser avec le sens usuel du langage, de rompre une bonne fois l'armature, de faire sauter le carcan [...]" (Artaud, Antonin. Le théâtre et son double. Paris: Gallimard, 1964: 153).
} 
necessária e insuperável entre ambos, será o elemento propiciador de uma reflexão acerca da linguagem poética. A prática de tradução põe necessariamente em cena uma relação com a alteridade, na medida em que o tradutor se vê confrontado com um idioma estrangeiro, que não pode ser totalmente assimilado por sua língua natal. A tarefa tradutória pode lançar luz sobre a prática poética porque ambas necessitam de uma espécie de maturação das palavras, um processo de gênese e nascimento do autor no seio de uma nova linguagem, de uma língua que, apesar de ser sua, torna-se também estrangeira pelas alterações que sofre em sua estrutura.

O autor é, então, aquele que emerge a partir dessa deformação operada no registro da linguagem; não é um sujeito que se utiliza das palavras como sua expressão própria, isto é, como um discurso que pudesse representá-lo, mas, ao contrário, como já havia anunciado Rimbaud no tão comentado "Je est un autre” de "Cartas do vidente”, alguém que emerge a partir do contato com a alteridade. Do mesmo modo, o que Artaud punha em questão era também o esquema representacional definido como a operação de um sujeito do conhecimento em direção a um objeto a ser conhecido. Para Artaud e Rimbaud, a palavra poética não é um instrumento mediador entre sujeito e objeto, muito menos uma espécie de espelho através do qual o sujeito, que já estaria dado anteriormente ao ato poético, poderia representar-se. A palavra poética é habitada por uma estranheza: é algo da ordem do acontecimento que permite a eclosão do poeta - sua emergência como outro - em decorrência do ato de produção da obra.

Em Suppôts et suppliciations, Artaud rechaça, de um só golpe, tanto a sabedoria expressada através da filosofia, das ciências matemáticas e das ciências ocultas, como também a anatomia e o saber médico sobre o corpo. Os alicerces que suportam as ciências, a filosofia e a medicina colocam em cena a relação de representação entre sujeito e objeto, apontando para a fixação de um ato de conhecimento que é exatamente o que Artaud pretende dissolver:

Eu tenho ódio da filosofia, da magia, do ocultismo, J'ai la haine de la philosophie, de la magie, de l'occultisme,

do esoterismo, da yoga, como o tenho também da anatomia, de l'ésotérisme, de la yoga, comme j'ai celle de l'anatomie,

digo da ANATOMIA, da medicina, da aritmética, je dis de l'ANATOMIE, de la médicine, de l'arithmétique, 
da álgebra, da trigonometria, do cálculo diferencial, de l'algèbre, de la trigonométrie, du calcul différentiel,

e da precessão dos equinócios, et de la précession des équinoxes,

e tenho também, e ninguém me acreditará talvez, ódio intestino et j'ai aussi, et nul ne me croira sans doute, la haine intestine

da poesia.

de la poésie.*

"Artaud, Antonin. "Suppôts et suppliciations". Em: Oeuvres complètes XIV. Paris: Gallimard, 1978: 28).

Por último, rechaça também a poesia, e aqui devemos entender esse gesto como a recusa de certa poesia, que seria a representação de um sujeito-autor e não sua produção, como também de uma escrita que estaria comprometida apenas com interesses estéticos e não veria no trabalho com a linguagem a possibilidade de uma ação efetiva, capaz de desarticular os campos do conhecimento e engendrar novas formas.

Entretanto, se Artaud proclama o seu ódio contra a magia e o ocultismo, há, por outro lado, uma relação bastante complexa que estabelece entre a poesia e a religião. De acordo com Rey, a tradução de Poe aparecerá, para Artaud, como uma dimensão a partir da qual ambas se encontram ${ }^{1}$, uma vez que o poema "Israfel" é a apresentação da figura de um Anjo que, através de seu canto, forma o mundo, dá vida ao céu e à terra. A voz do Anjo é a voz do poeta, cujo canto parte do próprio corpo, do coração:

No céu vive um coração de que as fibras são as cordas de um alaúde/ como a alma de uma labareda, no céu mais alto./ Não há tão selvagem canto no fundo do absoluto como/ o canto deste alaúde em voragem/ angélica, que é a corda vibrante do coração do Anjo/ Israfel."

Assim, o ponto em que a poesia assume uma dimensão sagrada será, para Artaud, o lugar em que a palavra é capaz de tornar-se potente, vital, detentora de uma força viva. Não devemos, todavia, enxergar de forma simplificadora essa imbricação entre poesia e sagrado como sendo a busca de uma idade do ouro, de um momento primeiro situado fora do tempo, que se traduziria por uma origem ou unidade perdida. O sagrado

${ }^{1}$ Aqui, apenas assinalando a leitura de Rey. No presente trabalho, procuraremos compreender a poesia com base em uma relação com o sagrado, e não com a religião.

" (Helder, Herberto. Doze nós numa corda. Lisboa: As. sírio \& Alvim, 1997: 21). 
não é, como poderíamos ser levados a pensar, o lugar de um encontro com o mundo primitivo. O caráter sagrado do ato poético como instauração da origem - e não sua recuperação através de um gesto nostálgico - será avaliado adiante. ${ }^{2}$

Trata-se de ver a poesia como possibilidade de transformação, de descoberta de um outro modo de estar na linguagem, ou de refazer a língua francesa, como dizia Artaud. Ora, se Artaud padecia dos efeitos de uma linguagem rígida da psiquiatria, do mundo empobrecido pela univocidade da comunicação, era preciso fazer com que as palavras lhe possibilitassem uma autonomia, uma outra forma de posicionamento. É no trabalho de tradução, no abismo que se abre entre as línguas, no contato com o estranho, com o estrangeiro, que Artaud poderá descobrir a sua própria dicção, inventar a sua linguagem ${ }^{3}$.

O projeto de recriação da linguagem e de construção do corpo seria, necessariamente, uma ação capaz de instaurar um regime de forças, a partir do qual haveria uma identificação entre poesia e vida, o que permitiria a atuação direta da primeira sobre a segunda. A proposta de um teatro da crueldade, formulada alguns anos antes do período no asilo de Rodez, já repousava no encontro de uma materialidade da linguagem cênica, o que apontaria para uma não separação entre esta e o corpo, constituindo-se como uma linguagem do próprio corpo.

Se uma das bases da poética de Artaud é a construção de um outro corpo, esvaziado das funções orgânicas que o submetem a um regime ditatorial, castrador, e que cerceiam o seu potencial $^{4}$, a outra seria a construção de uma nova linguagem, que também pretende escapar a uma ditadura da representação e do sentido. Trata-se de uma poética do grito e do golpe, de uma poesia da ação e não da representação:

Conheço um estado fora do espírito, da consciência, do ser, Je connais un état hors de l'esprit, de la conscience, de l'être,

e em que não há mais palavras nem letras, et qu'il n'y a plus ni paroles ni lettres,

${ }^{2}$ Adiante, estabeleceremos, tomando como base um texto de Jean-Luc Nancy, a diferença entre a religião e o sagrado.

${ }^{3}$ Podemos citar como exemplo da criação de uma nova linguagem as glossolalias do poeta: "ya menin/ fra te sha/ vazile/ la vazile/ a te sha menin/ tor menin/ e menin menila/ ar menila/ i inema imen". Cf. Artaud, Antonin. "Suppôts et suppliciations" Ob. cit.: 31 .

${ }^{4} \mathrm{O}$ corpo sem órgãos é uma das principais propostas de Artaud, tomada como modelo de pensamento para Gilles Deleuze e Félix Guattari no livro Mil platôs. 
mas onde se entra através de gritos e golpes. mais où l'on entre par les cris et par les coups.

E não são mais sons ou sentidos que emergem, Et ce ne sont plus des sons ou des sens qui sortent,

não são mais palavras

plus des paroles

são CORPOS. mais des CORPS.*

"(Artaud, Antonin. "Sup pôts et suppliciations". Ob. cit.: 30$)$

Assim, é no esvaziamento do corpo, tal como escreve Artaud em Suppôts e suppliciations ${ }^{5}$, na recusa a dar-lhe uma forma, e na liberação da escrita de um molde fixado pela sintaxe, pela lógica e pelo sentido, que formularemos aqui a hipótese de uma escrita transgressora, muito próxima do pensamento do informe de Bataille, já que, como afirma Didi-Huberman no ensaio “Comment déchire-t-on la ressemblance?”, a transgressão em Bataille é sempre uma transgressão da forma, tendo por objetivo não uma anulação completa das formas, mas a dissolução de estruturas cristalizadas, de modo a proporcionar a irrupção do novo:

Reivindicar o informe não quer dizer reivindicar não-formas, mas principalmente se engajar num trabalho de formas equivalente ao que seria um 'trabalho' de parto ou de agonia, quer dizer: uma abertura, uma ruptura, um processo doloroso que oferece alguma coisa à morte e, nessa negatividade mesma, inventa alguma coisa absolutamente nova, dá algo à luz, mesmo que seja a luz de uma crueldade no trabalho com as formas e com as relações entre as formas, isto é, uma crueldade com as semelhanças.

Didi-Huberman, nesse texto, procura investigar o sentido de uma semelhança desclassificante ${ }^{6}$, uma semelhança que derrubaria a hierarquia entre o modelo e a cópia. É nesse sentido que entendemos também a atividade tradutória. A tradução não

5 “[...] um corpo,/ sem espírito,/ sem alma,/ sem coração, [...]/ sem língua,/ sem amígdala,/ sem glote,/ sem glândulas,/ sem tireóide,/ sem orgãos,/ sem nervos,/

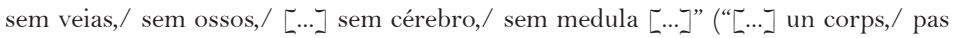
d'esprit,/ pas d'âme,/ pas de coeur, [...]/ pas de langue,/ pas de luette,/ pas de glotte,/ pas de glandes, / pas de corps thyrö̈de,/ pas d'organes,/ pas de nerfs, / pas de veines,/ pas d'os, / [...] pas de cerveau,/ pas de moelle,/ [...]”. Cf. Artaud, Antonin. "Suppôts et suppliciations" (Ob. cit.: 13).

${ }^{6}$ Lembremos que Didi-Huberman trabalha com essa idéia de semelhança desclassificante a partir do verbete "Informe", do "Dictionnaire critique", presente na revista Documents, dirigida por Bataille.

"(Didi-Huberman, Georges. "Comment déchire.t.on la ressemblance?". Em: Hol. lier, Denis (dir.) Georges Bataille après tout. Paris: Berlin, 1995: 115). 
seria, portanto, a produção de um semelhante ao original numa língua estrangeira, mas sim de algo que é em tudo dessemelhante ao original, algo que produz uma deformação, uma monstruosidade. Do mesmo modo, também Benjamin, no famoso A tarefa do tradutor, afirma que, para apreender a relação autêntica entre original e tradução, é preciso abandonar uma teoria da imagem-cópia, já que o texto traduzido, ao mesmo tempo que representa a sobrevida do original, comporta também a sua (do original) transformação, o que quer dizer que é justamente em sua mutação que ele pode continuar a existir.

Assim, a empresa antigramatical assinalada por Artaud e a sua proposta de criação de um corpo sem órgãos podem ser compreendidas dentro do projeto de recusa à semelhança, isto é, de recusa a uma prática da representação, em prol de um pensamento do informe, daquilo mesmo que tem por objetivo agir contra as formas fixas, submetendo-as a um processo de renovação.

Retornemos, agora, ao gesto assumido por Herberto Helder ao acrescentar o seu nome à lista dos tradutores de Poe. Ao publicar a sua versão do poema "Israfel", fazendo constar, ao lado da sua, a de Mallarmé e a de Artaud, Helder repete o gesto de definição de uma poética, que julgamos apresentar muitos pontos de contato com as ambições do segundo ${ }^{7}$. Pois Herberto Helder, assim como Artaud, situa as possibilidades do fazer poético num pensamento sobre o corpo. Uma primeira diferença, entretanto, deve ser assinalada: Artaud parte de um corpo completamente esfacelado, alijado do discurso, submetido às torturas e aos constrangimentos dos asilos psiquiátricos. Um corpo que será preciso reconstruir sobre novas bases, esvaziando-o de suas funções puramente orgânicas, para que ele possa receber e suportar a linguagem que é produtora do poeta, uma linguagem que se define para além da necessidade de sentido. Já Herberto Helder parte de um corpo que deve ser deformado, que será preciso abrir, para que se dê a realização da tarefa poética. Mais uma vez, podemos fazer um paralelo com "Cartas do vidente", de Rimbaud, em que o jovem poeta indica a necessidade de um método de deformação da alma e do corpo, de um trabalho a ser realizado: "Mas se trata de tornar

\footnotetext{
${ }^{7}$ Não deixa de ser interessante lembrar mais uma vez que Helder realiza sua tradução não a partir do poema de Poe, e sim da tradução de Artaud, o que contribui para estabelecer um nítido elo entre os dois.
} 
a alma monstruosa: a exemplo dos comprachicos, pois! Imagine um homem implantando e cultivando verrugas no seu próprio rosto"*.

Mas se os pontos de partida de Artaud e Helder parecem diversos, os pontos de chegada são, em muito, bastante convergentes. Para ambos, trata-se de uma operação de potencialização do corpo, de uma abertura dos sentidos que não estaria mais identificada com uma servidão anatômica ou com um corpo submetido ao funcionamento de seus órgãos. Em Herberto Helder, observamos a abertura do corpo através do exercício da palavra, como no poema que inicia o livro intitulado Do mundo:

[...] Abre-me todo a força da palavra encharcada, abre-me através de abdómen e diafragma, os pulmões, os brônquios, traquéia, a glote, palato, e dentes, língua,

o côncavo da boca: um canto, a ventania do corpo.*

A violência deformadora, que incide tanto sobre o corpo como também sobre a própria linguagem, é o que nos permite alargar o pensamento a respeito da prática de tradução e da poética de Herberto Helder. Esse gesto de abertura do corpoato de violência extrema que pode ser observado em outros momentos de sua obra ${ }^{8}$ - sinaliza uma passagem do interior para o exterior, de um corpo dilacerado a partir do qual se produz o espaço do mundo e a própria voz do poeta. O corpo aberto, no caso de Herberto Helder, ou esvaziado de seus órgãos, no caso de Artaud, remete a um espaço que é, ao mesmo tempo, proximidade e distância entre o eu e o mundo. É uma espécie de fenda, de corte ou passagem a partir da qual se efetiva uma comunicação entre interior e exterior.

Assim como a poética de Artaud procurava encenar um mecanismo de eclosão do novo, também a de Herberto Helder está à procura de uma palavra que faça irromper uma potência fulgurante e transformadora:

\footnotetext{
${ }^{8}$ Podemos citar uma passagem de $O$ corpo o luxo a obra: "E o golpe que me abre desde a uretra/ à garganta/ brilha/ como o abismo venoso da terra. [...] Na límpida teia das mãos,/ a colher que se arqueia/ desde/ a traça alimentar à costura cirúrgica/ da garganta/ onde a voz rebenta/ num buraco de sangue. Mas as cabeças, que olham/ pelos lados/ novos/ de gárgulas jorrando toda a força/ da luz interna,/ vivem da energia/ da nossa graça, da ferida/ da elegância. A violência envenena-me”. Cf. Helder, Herberto. Ou o poema contínuo (Ob. cit.: 351).
}

" (Rimbaud, Arthur. Oeuvres complètes. Paris: Galli. mard, 1972: 251).
Poemar, Herberto. Ou sírio e Alvim, 2004: 515). 
"(Helder, Herberto. Ou o poe. ma contínuo. Ob. cit.: 32).
Penso que deve existir para cada um uma só palavra que a inspiração dos povos deixasse virgem de sentido e que, vinda de um ponto fogoso da treva, batesse como um raio nos telhados de uma vida, e o céu com águas e astros caísse sobre esse rosto dormente, essa fechada exaltação.*

A busca dessa palavra tem sido, por vezes, lida como a tentativa de recuperação de uma língua pré-babélica, de uma palavra fundadora que remeteria a um tempo anterior ao gesto adâmico que representou a perda do paraíso. Em outras palavras, a poética de Herberto Helder pode aparecer associada a um movimento de retorno a uma origem, pensada como um tempo primeiro, tempo mítico de aliança entre o homem e o mundo, que remeteria à plenitude e à harmonia de uma unidade primordial. Partindo desse pressuposto, sua poesia assumiria, então, uma dimensão religiosa, em que o ato poético se tornaria também uma espécie de ato de conciliação. A prática da tradução, no entanto, evidencia um outro aspecto que põe em questão esse lugar mitificante da poesia.

\section{A tradução como prática de escavação}

Em A tarefa do tradutor, Benjamin parte do pressuposto de que o essencial numa obra literária não é a comunicação. Se a tradução de uma obra literária tiver por objetivo a comunicação, acabará deixando de fora, necessariamente, o que nela há de mais importante, o poético. Ao rechaçar a comunicação, Benjamin afirma, como já assinalamos, que a relação entre original e tradução não está apoiada numa idéia de cópia, e que a tradução seria impossível caso se fundamentasse num princípio de semelhança.

A tradução, ao mesmo tempo que aponta para a permanência e a sobrevida do original, compreende também a sua mutação, sua transformação. Mas não é apenas isso, pois o gesto do tradutor, ao tentar atravessar a diferença entre as línguas, modifica tanto o original quanto a própria língua na qual o texto é traduzido. $\mathrm{O}$ ato de tradução produz, portanto, a emergência de algo novo no seio do presente, algo que remete a um passado, mas um passado que não está situado fora da história, e sim 
um passado que também surge modificado pelo próprio gesto de tradução. A temporalidade, tal como a entende Benjamin, não é a de um tempo homogêneo que se desenvolve numa sucessão cronológica, mas de um tempo formado por rupturas que destroem a linearidade da história; tempo pontuado por instantes carregados de singularidade.

Didi-Huberman, no livro O que vemos, o que nos olha*, ao pensar o caráter diáletico de uma obra de arte, formula essa irrupção do novo como uma atividade semelhante à escavação. Um objeto, ao ser descoberto através de uma escavação, altera tanto o presente em que surge, como também o solo do passado. Assim, o objeto não emerge do passado numa espécie de "pureza” que faria dele algo totalmente desvinculado do momento atual, ele não pode ser apartado da história que provocou a sua irrupção. Ao emergir na atualidade, ele já é portador de um potencial de contaminação que, em um único gesto, modifica o presente e o passado.

Do mesmo modo, se pensarmos no gesto instaurador que é a prática poética - e no que ela tem de semelhante à tradução -, parece-nos bastante plausível que esse ato não seja compreendido como uma tentativa de recuo a um passado a-histórico, como a busca de uma origem situada fora do tempo, num momento primeiro em que a linguagem não estaria divorciada das coisas. É certo que o ato poético deseja ser um ato instaurador, mas devemos entender essa instauração como o modo de funcionamento de uma potência desagregadora do presente, e não como o retorno nostálgico a uma origem perdida no passado; o ato poético é algo da ordem de um acontecimento. Seguindo o pensamento de Didi-Huberman, poderíamos dizer que o ato poético não busca regressar a uma origem, ele é a própria origem, mas uma origem que é também histórica, na medida em que é a partir dela que se constitui uma nova temporalidade.

Voltando ainda a $A$ tarefa do tradutor, devemos lembrar que Benjamin utiliza a palavra Aufgabe, que significa tanto tarefa quanto renúncia. O que essa dupla significação assinala é justamente o caráter de impossibilidade da tradução como um retorno à origem. A origem aparece, portanto, como o horizonte para o qual o gesto de traduzir está voltado, apontando também para a impossibilidade de atingi-lo. A origem, pensada dessa forma, não é a recuperação de algo perdido, e sim o gesto a partir do qual se instaura uma separação, que é a própria diferença entre as línguas, a distinção entre o texto original e o texto traduzido.
" (Didi-Huberman, Geor. ges. O que vemos, o que nos olha. São Paulo: Ed. 34, 1998). 
"(Helder, Herberto. Ouolof Lisboa: Assírio \& Alvim, 1997: 44).
"(Helder, Herberto. Ouolof. Ob. cit.: 51)
A diferença entre as línguas permite que pensemos a atividade de escavação em outro sentido ainda. Esse outro sentido também está anunciado em A tarefa do tradutor, quando, no final do texto, Benjamin cita Pannwitz, que censurava o tipo de tradução realizada pelos alemães, acreditando que a tradução deveria provocar um alargamento da língua do tradutor - o que faria com que esta se tornasse uma língua estranha-, e não ser uma tentativa de tornar mais familiar a língua estrangeira. Essa tarefa resultará, portanto, em alargar e aprofundar a sua própria língua, escavar em seu interior um oco de sentido, esvaziá-la de sua lógica, libertá-la de sua ordenação sintática. Herberto Helder, no livro Ouolof, escreve uma nota a respeito de sua tradução de um poema dos índios Caxinauá chamado "A criação da lua”, em que assinala o alargamento da língua portuguesa pelo atrito com a língua estrangeira, produzindo "um português desarrumado, errado, libertado, regenerado, recriado"*.

Pois o que está em questão na atividade de tradução, tal como a entende Herberto Helder, não é a busca de uma semelhança entre as línguas, e sim a possibilidade de deformação que ela pode representar para a língua do tradutor. Lembremos, aqui, as famosas "traduções monstruosas” de Sófocles realizadas por Hölderlin e citadas por Benjamin ainda em A tarefa do tradutor. A tradução monstruosa é aquela que, em prol da literalidade, da materialidade da linguagem, baniu uma relação que repousaria sobre o critério da semelhança entre as línguas, uma relação de representação entre o modelo e a cópia. O que a tradução monstruosa evidencia, ao contrário, é que, a partir da relação entre o original e o texto traduzido, produz-se um esburacamento na língua do tradutor, tornando-a deformada, monstruosa.

A deformação da língua é o ponto visado por Herberto Helder ao traduzir, por exemplo, o poema "A criação da lua":

A lua quando se deitou: lua deitada está,

fazei não! de lobonauá a cabeça deitada, fazei!

Àqueles ensinou, acabou, seus fios pôs na boca, em cima se pendurou, foi. Céu

dentro entrou, seus olhos arrancou, estrelas

fez, sua cabeça lua se tornou, de seu sangue arco-íris

fez. $[\ldots]^{*}$ 
O interesse de Herberto Helder pelas culturas primitivas ${ }^{9}$, tal como se vê na tradução desse poema dos Caxinauá, tem sido interpretado como um desejo de retorno a um mundo ancestral, não contaminado pela civilização. Acreditamos, todavia, que o desejo desse encontro nostálgico não é o que motiva a poética do autor; o ato poético não deve ser entendido como uma oposição entre a cultura moderna ocidental e a cultura primitiva, em que haveria uma valorização da segunda em detrimento da primeira. Não se trata de um olhar melancólico sobre o passado que leria o mundo ancestral como um lugar de beleza e de plenitude, ao passo que o mundo moderno seria totalmente empobrecido e esvaziado pela técnica. Parece-nos que Helder efetivamente procura a possibilidade de deformação desse mundo mesmo, realizada através do alargamento da linguagem e da destruição de sua lógica. Ainda na nota sobre a tradução do poema dos Caxinauá, Helder escreve: "Temos diante de nós uma poderosa dicção mítica, mágica, lírica, transgredindo em todas as frentes a norma da palavra portuguesa. Este transtorno faz-se ele mesmo e imediatamente substância e acção poéticas"*.

Ao trazer para a poesia esse substrato mítico, Helder não procurará reviver os mitos ou voltar-se para eles como se empreendesse uma busca arquetípica, mas sim situar-se numa posição que permita ultrapassá-los. Esse seria, para Didi-Huberman, o modo de lidar com o passado que caracteriza a arte moderna: "Quando uma obra consegue reconhecer o elemento mítico e memorativo do qual procede para ultrapassá-lo, quando consegue reconhecer o elemento presente do qual participa para ultrapassá-lo, então ela se torna uma 'imagem autêntica' no sentido de Benjamin"*.

A 'imagem autêntica' a que Didi-Huberman se refere é, portanto, a que nos faz reconvocar o passado, não para retor-

\footnotetext{
${ }^{9}$ Aqui, devemos assinalar mais um ponto de contato entre a poética de Herberto Helder e a de Artaud, já que o segundo também manifestou enorme interesse pelas culturas primitivas, sendo levado inclusive a participar de rituais junto aos Tarahumaras, no México. Mas, de acordo com Ana Kiffer em seu estudo sobre o poeta, esse interesse não deve ser entendido como um desejo de retorno a um mundo puro que estaria em oposição à cultura ocidental. A autora pensa esse interesse no sentido de uma contaminação: "A contaminação estaria generalizada. Se poderia mesmo dizer que aqui o teatro da crueldade é a contaminação. Não há um mundo puro, mas a necessidade de contaminar os mundos, para finalmente fazer dançar o corpo humano". Cf. Kiffer, Ana. Antonin Artaud. Uma poética do pensamento (Ob. cit.: 60).
} "(Didi-Huberman, Geor-
ges. O que vemos, o que nos
olha. Ob. cit.: 193). 
narmos a ele, e sim para que o reconfiguremos no presente, alterando, num mesmo gesto, tanto um quanto o outro. Seria esse, provavelmente, o sentido da transgressão que Helder aponta em relação à 'norma da palavra portuguesa', transgressão essa que tem como objetivo modificar o substrato da língua, identificando-se com a 'ação poética'.

\section{Para uma leitura do sagrado}

A presença do sagrado na poesia de Herberto Helder é, por vezes, apontada como a substancialização de uma origem primordial à qual é preciso remontar, do mesmo modo que sua poética é, por vezes, lida num sentido religioso, que teria como finalidade re-ligar o homem à natureza, e a palavra poética à palavra divina. É a partir de uma idéia de distinção, todavia, que o caráter sagrado de sua poesia pode ganhar outro relevo. Assim, esse sentido do sagrado pode ser pensado tal como o fez Jean-Luc Nancy no livro Au fond des images. Para Nancy, o sagrado se opõe à religião, uma vez que esta assinala a ligação, ao passo que aquele assinala a cisão. O sagrado é algo da ordem do distinto, da distinção e da distância; é como um traço, um corte a partir do qual as coisas se distinguem umas das outras.

Esse sentido pode ser perfeitamente recuperado para que reflitamos sobre a tradução. Se a tradução não é a busca de fidelidade e de representação de uma língua por outra, se o que ela dá a ver é justamente o abismo que as separa, podemos sustentar que a marca da tradução, a diferença evidente entre as línguas - e podemos chamá-la também de distinção entre as línguas - remete a esse caráter sagrado, que num mesmo movimento institui a aproximação e a distância entre o original e a tradução. Assim, mais do que a semelhança entre o texto original e o texto traduzido, o que o ato de traduzir evoca é a distância entre ambos.

No livro em questão, Nancy postula o caráter sagrado das imagens e assinala que estas não são apenas visuais, mas também musicais, poéticas, táteis etc. Desse modo, as imagens poéticas são também marcas distintivas, imagens a partir das quais algo se dá a ver através de um movimento de separação. É nesse sentido que as imagens poéticas podem ser entendidas como traços que possuem uma força originária, lugar em que algo começa. Herberto Helder, no “Texto 2", de Antropofagias, assinala essa potência originária da palavra poética: 
[...] 'escrita e escritura' desenvolvidas pelo silêncio

que as não ameaça mas de si as libera como uma

borboleta ávida uma dona do espaço

visível proprietária da luz e sua extensão

'sinal' daquilo que se abriu por sua energia mesma

e nenhum arrepio de horror sequer um 'transe'

fere o flanco oferecido ao mundo

apenas um 'nascimento' o ritmo trabalhado noutro e trabalhando

outro ritmo como a malha das artérias

um mapa uma flor quentíssima em fundo de atmosfera.*

" (Helder, Herberto. Ou o poema contínuo. Ob. cit.: 276).

A escrita relaciona-se com um "sinal”, algo como a marca de um "nascimento”, que no poema toma a forma de uma operação semelhante ao traçado de um "mapa”; operação que também propicia a diferenciação entre a "flor quentíssima" e o "fundo de atmosfera”. A imagem poética carrega em si uma força de distinção, uma "energia” a partir da qual ela se apresenta, separando-se do "silêncio". Ela não visa reportar-se a uma origem, ela é a apresentação de uma força: "visível proprietária da luz" que instaura a distinção. Como observa Nancy, não é que a imagem (poética ou de outra ordem) represente essa força, mas que ela é a própria força, um choque que dá a ver:

Se é possível que o mesmo traço, a mesma distinção, separe e faça comunicar $[\ldots]$ é porque o traço da imagem $[\ldots]$ é ele próprio [...] sua força íntima: pois a imagem não representa essa força íntima, ela é essa força, ela ativa-a, ela a expande e ela a contrai, ela a extrai retendo-a, e é assim que ela nos toca.*

Assim, se a imagem poética nos toca, é porque ela é dotada de um poder que nos atinge, que nos mobiliza, e essa seria talvez a força principal da palavra poética, como também das outras formas de arte. A força de uma obra de arte é, portanto, a de ser um agente de inquietação, de desagregação das formas, de ruptura com o sentido. Desse modo, a imagem poética é também da ordem do distinto, uma vez que retira a linguagem do mundo utilitário das coisas, que separa as palavras da necessidade de representação.

Didi-Huberman fala desse poder violento da obra de arte como sendo uma "beleza estranha e única”, já que as imagens artísticas carregam em si uma potência transformadora e inquietante que age sobre o campo do conhecimento, produzindo efeitos de sentido. Para ele, essa capacidade de a imagem rein- 
"(Didi-Huberman, Geor. ges, O que vemos, o que nos olha. Ob. cit.: 178).

" (Helder, Herberto. Photomaton \& Vox. Lisboa: Assí rio \& Alvim, 1995: 137) ventar o presente revela o seu modo de participar da "sublime violência do verdadeiro" . A "violência do verdadeiro" inerente à imagem, essa potência da palavra poética, reencontra o projeto de Artaud, que visava à produção de uma linguagem não representativa, uma linguagem da ação, projeto que se descortina justamente no teatro da crueldade.

Desenha-se, portanto, um vínculo intrínseco entre arte e violência. A arte autêntica é necessariamente violenta, na medida em que produz imagens inquietantes, provocativas, imagens que rompem com as formas fixadas pela cultura, que põem em xeque o pensamento e forçam-no a uma inquietação incessante, à perpetuação dos enigmas. Como assinala Helder em Photomaton e Vox:

A verdade é a reposição permanente dos enigmas. Porque não há unidade. Mas enquanto se fez o esforço das inquirições mantevese um nó central: a energia das hipóteses, a sua força propulsora, os mitos da verdade. Ouçam: é bom mexer nas palavras, organizá-las num espaço, estabelecer-lhes os movimentos de rotação e translação umas com as outras. Cria uma tensão que evita a fuga completa da vida interior. Este é outro modo de ver a questão, mas sabe-se imediatamente que é outro modo do mesmo modo. ${ }^{*}$

O projeto no qual Artaud e Helder estão envolvidos não pode, portanto, ser entendido como puramente estético, daí o privilégio que ambos concederam - e, juntamente com eles, não podemos deixar de pensar em Bataille - à experiência corporal. Se estamos aqui estabelecendo um paralelo entre a prática de tradução e o fazer poético, é porque ambos colocarão em evidência uma escrita transgressora, presente nos dois poetas apontados, já que, para eles, a poesia representará a possibilidade de produzir formas transgressivas ${ }^{10}$, rompendo com a hierarquia estabelecida pelo modelo representacional entre o original e a cópia, entre sujeito e objeto, no mesmo gesto em que acena para a possibilidade de renovação do presente e da constituição do próprio poeta.

${ }^{10}$ Como assinala Didi-Huberman a respeito do trabalho de Bataille na revista Documents: "A questão que se pode pôr desde então [...] seria aqui compreender de que maneira transgredir as formas significa produzir formas transgressoras, de que maneira destruir as semelhanças significa produzir semelhanças destruidoras" Cf. Didi-Huberman, Goerges. “Comment déchire-t-on la ressemblance?” (Ob. cit.: 116). 
